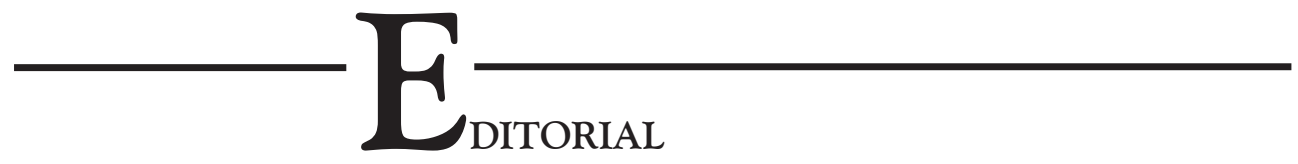

\title{
Práticas Religiosas e a PRodução de TERRITORIALIDADES, DESLOCAMENTOS, FRONTEIRAS, RITUAIS E DEVOÇÃO
}

\author{
Carly Machado* \\ *Universidade Federal Rural do Rio de Janeiro \\ Seropédica - RJ - Brasil \\ Emerson Giumbelli** \\ **Universidade Federal do Rio Grande do Sul \\ Porto Alegre - RS - Brasil \\ Christina Vital*** \\ ***Universidade Federal Fluminense \\ Niterói - RJ - Brasil
}

Os artigos apresentados neste número são compostos por textos do fluxo contínuo da Revista Religião \& Sociedade. Suas abordagens são variadas, abrangendo diferentes práticas religiosas, territórios e temáticas.

Em alguns destes trabalhos a questão territorial é uma marca importante da análise. O artigo de Darnisson Viana Silva e Rodrigo de Azeredo Grünewald intitulado "Velhas e Novas Crenças: sobre o encontro de religiosidades em uma vila amazônica" analisa a convivência de religiosidades em Alter do Chão (Santarém PA). Suas reflexões nos levam a pensar sobre as características deste território com- 
posto de forma densa por moradores, turistas e viajantes na produção de um cenário particular de formação de fronteiras simbólicas, configurações históricas e "localismos" do campo religioso. Segundo os autores, na "floresta de crenças" de Alter do Chão desenvolvem-se novas maneiras de vivenciar "velhas" e variadas crenças (que envolvem catolicismo, umbanda, novos movimentos religiosos, yoga, dentre outros) com uma notável tendência para o diálogo e complementações religiosas.

Também no artigo "Guerra de Xangô: ritual, perseguição e conflito na formação do campo religioso afro-sergipano" de Petrônio Domingues, o território de Sergipe é um aspecto de destaque nas questões desenvolvidas no texto. A partir da controvérsia em torno do julgamento de Evaristo José dos Santos em 1939, acusado da morte de Teodomiro, esta associada à "macumba", Domingues analisa a formação do Xangô sergipano e os estigmas e estereótipos imputados às religiões da diáspora negra naquele território. $\mathrm{O}$ autor evidencia como os campos da imprensa, da polícia e da justiça participam da produção deste problema que se inscreve nos debates mais recentes sobre intolerância religiosa, também chamada de racismo religioso, informando, assim, sobre práticas locais e supralocais em diferentes temporalidades..

Anna Beatriz Zanine Koslinski e Isabel Cristina Martins Guillen, em seu artigo "Maracatus-Nação e a Espetacularização do Sagrado", situam sua pesquisa no estado de Pernambuco e a partir deste território apresentam suas questões sobre a "sacralização" dos maracatus-nação. Entendendo "sacralização" como um processo no qual elementos relacionados às religiões de matriz africana são multiplicados e colocados em evidência nas performances dos maracatus-nação em Pernambuco, as autoras discutem os jogos de poder e interesse que produzem e são produzidos por estas práticas, articulando cultura, turismo, religião e mercado.

Um segundo conjunto de artigos aqui apresentados têm por temática a questão dos deslocamentos, transformações, trânsitos e a formação de fronteiras a partir da questão da religião e do religioso. O artigo de Norberto Decker com o título "Um debate acerca da formação da secularidade católica brasileira a partir das migrações européias do fim do século XIX" propõe uma reflexão sobre a formação da sociedade brasileira em sua relação com o Catolicismo, considerando a questão das migrações e das tensões por elas produzidas na virada do século XIX para o século XX. A partir do "caso Idalina", no qual grupos anarquistas denunciaram um padre pelo assassinato de uma menina no Orfanato Cristóvão Colombo em São Paulo, Decker analisa a presença católica no espaço público brasileiro, o modo como esta presença define os rumos das denúncias em torno do caso, e como, a partir destes desdobramentos, pode-se compreender aspectos importantes sobre o modo como catolicismo conseguiu se secularizar no Brasil, com destaque para sua inserção nos campos da educação e da assistência social.

Tendo por foco a delicada fronteira entre judaísmo e cristianismo, Paula Fontanezzi, em seu texto "Judaísmo messiânico, genealogia e agência: relações entre judeus e não judeus em sinagoga messiânica paulistana" analisa um grupo da cidade de São Paulo que articula práticas judaicas com crenças em Cristo. A autora se 
interessa pela maneira como judeus e cristãos são representados e imaginados neste contexto do judaísmo messiânico. Evidenciando como, neste campo, são acionadas ideias como "Casa de Israel", "Israel espiritual", "filhos de Jesus", "filhos de Jacó" para a construção e negociação destas fronteiras, Fontanezzi destaca a importância de se pensar sobre a ideia de "performatividade" neste processo de formação de "judaicidades" e "cristianitudes".

O artigo "Muçulmanos no Brasil: uma análise socioeconômica e demográfica a partir do Censo 2010" de Cristina Maria Castro e Elaine Meire Vilela apresenta um perfil socioeconômico e demográfico da comunidade muçulmana no Brasil. Ao debruçarem-se sobre informações variadas acerca destes sujeitos (tais como local de moradia, país de nascimento, sexo, raça, casamento e atividade econômica - dentre outras), além de formularem uma significativa análise das informações do Censo 2010, as autoras desenvolvem ainda interessantes comparações dos dados quantitativos discutidos com Censos de anos anteriores, procurando deixar pistas sobre as transformações deste campo no tempo. Destaca-se neste artigo a importância referida pelas autoras aos estudos de religião em relação aos dados do Censo, tal qual largamente pontuado por Clara Mafra ao longo de seus estudos sobre o tema.

Ainda neste campo de questões sobre transformações e deslocamentos, o artigo de Maria Regina Cariello Moraes, com o título "O desencantamento da meditação: da união mística ao fitness cerebral" apoia-se em teses weberianas para trazer importantes contribuições para reflexões contemporâneas sobre a relação entre religião e saúde. Referindo-se aos impactos do deslocamento da meditação - com sua referida origem asiática - para cenários urbanos, a autora analisa como a captura desta prática por "camadas privilegiadas e intelectualizadas" promoveu a "racionalidade terapêutica" da meditação e sua legitimação como estratégia no campo da saúde, particularmente da saúde mental. Analisando controvérsias em torno da meditação, sua assimilação em meios empresariais, e sua difusão pela mídia, Moraes enfatiza a perda dos elementos "místicos" da prática, e sua reconfiguração como ginástica cerebral ou "fitness" mental.

Dois artigos deste número destacam-se por suas contribuições aos estudos de rituais e da devoção. Em "Narrativas hagiográficas e devoção aos santos: notas sobre a (re)produção simbólica da santidade nos cemitérios", seu autor Hugo Ricardo Soares trata de práticas devocionais em cemitérios. Seu estudo localizado na cidade de São José dos Campos, em São Paulo, ocupa-se da descrição e análise dos rituais dos devotos em cemitérios, ao mesmo tempo que apresenta também uma abordagem da vida destes "santos de cemitérios", narrativas hagiográficas estas que aproximam de maneira muito interessante a vida dos santos das cidades com a vida nas e das próprias cidades. Trabalhando com alguns casos de devoção no mesmo cemitério, o autor toma sua diversidade para sistematizar observações acerca de perfis distintos de religiosidade.

O artigo de Raquel dos Santos Sousa Lima intitulado "Santa Rita de Cássia, rogai por nós”: uma análise da novena de Santa Rita de Cássia no Rio de 
Janeiro" apresenta uma análise baseada nas teorias do ritual, com destaque para a relação entre ritual, devoção e festa. A autora desenvolve uma rica descrição da novena que integra a devoção à tradicional festa de Santa Rita de Cássia no Rio de Janeiro, com ênfase na articulação entre os rituais e a questão de gênero. Os textos das orações que constituem a novena são analisados com especial atenção para características formais e para as condições de produção de seus efeitos.

O artigo de Ypuan Garcia Costa, com o título "Irmãos em Cristo", "mãe na fé" e "pai espiritual": filiação a Deus e parentesco humano" apresenta uma importante reflexão sobre a relação religião e parentesco no âmbito de um grupo católico de São Paulo. Ao enfatizar em sua análise a ideia de "Deus" como um potente elemento de configuração de parentescos humanos e religiosos (utilizando-se da categoria de "oniparente"), o autor discute os modos como, no dia a dia da comunidade católica estudada, suas particularidades e suas diferenças em relação a grupos protestantes, acontece a feitura de alianças por meio do fazer-se de novos irmãos, filhos, mães e pais.

Este número conta, ainda, com a resenha intitulada "Mantendo viva uma festa sem fim" de Iacy Pissolato Silvera e Marina Guimarães Vieira. Nela apresentam o livro "As forças do Jarê: Religião de matriz africana da Chapada Diamantina" de Gabriel Banaggia. Esta obra é resultado da tese de doutorado do autor na qual coloca em relevo o Jerê, uma tradição fruto da diáspora africana ainda pouco pesquisada no Brasil. A força do trabalho reside, não só na exploração de um campo pouco conhecido, mas também em uma etnografia realizada durante 14 meses na cidade de Lençóis (BA) onde Banaggia pôde acompanhar rituais em cerca de 15 casas ali presentes e a religião vivida pelos seguidores da tradição. Esta forma de peregrinação, como destaca o autor, conduzida em campo pelos interlocutores, possibilitou o acesso a diferentes formas de apreensão da religião. Essa transformacionalidade, nos termos de Lévi-Strauss, seria elemento fundamental para a continuidade e força do Jerê na região. Além da contribuição para as Ciências Sociais da religião, as autoras da resenha destacam o valor literário da obra que envolve o leitor capítulo a capítulo.

Ao longo de sua história, Religião e Sociedade manteve a prática de elaborar editoriais em todos os seus números. A partir do próximo haverá uma modificação. Nos números que contêm dossiês, será feita uma apresentação por parte dos seus organizadores. No entanto, naqueles de que participam apenas artigos de fluxo não haverá mais editorial. A função dos editoriais tem sido apontar chaves de leituras para os textos e apresentar uma síntese das ideias de seus autores. Contudo, a diversidade destes artigos em termos de temas, perspectivas e questões de pesquisa tem tornado esta tarefa insuficiente. Confiamos que nossos leitores poderão por si mesmos encontrar múltiplas chaves de leitura nos textos da revista, além de poderem recorrer aos resumos que os acompanham para acessar sínteses mais ricas.

Este trabalho está licenciado com uma Licença Creative Commons - Atribuição Não-Comercial 4.0 Internacional. 